Año LI. urtea

$127-2019$

Urtarrila-ekaina

Enero-junio

5

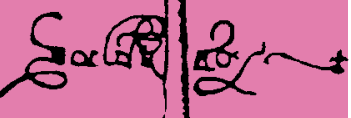

ats

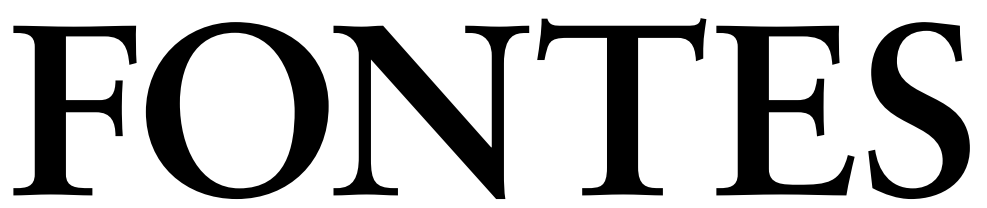

LINGVÆ

VASCONVM

STVDIA ET DOCVMENTA

SEPARATA

Mailegatze morfologikoa eta generoa euskaraz

Manuel Padilla-Moyano

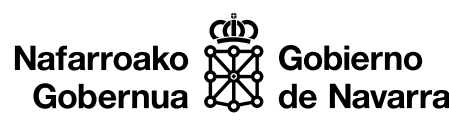

- 00 


\title{
Mailegatze morfologikoa eta generoa euskaraz
}

\author{
Préstamo morfológico y género en euskera
}

Morphological borrowing and gender in Basque

Manuel PAdilla-MoYANO

IKER UMR 5478 \& Université de Pau et des Pays de l'Adour

manuel.padilla@iker.cnrs.fr

Lan hau ondoko proiektuen babespean egina da: Monumenta Linguae Vasconum V: periodizazioa eta kronologia (Ekonomia eta Lehiakortasun Ministerioa, FFI2016-76032-P); Euskal Hizkuntzaren Historia eta Hizkuntzalaritza Historiko Konparatua (Eusko Jaurlaritza, GIC. IT698-13), Hizkuntzalaritza teorikoa eta diakronikoa: gramatika unibertsala, hizkuntza indoeuroparrak eta euskara (UPV/EHU, UFI11/14) eta Basque in the making: a historical look at a European language isolate (BIM, ANR 2017). Bihoa ene esker hoberena Beñat Oyharçabalentzat eta Blanca Urgellentzat, haien gidaritza eta aholkuengatik, eta Iván Igartuarentzat, lan honi ekarpen tipologikoa eginik. Halaber, Maider Bedaxagar eta Argitxu Camus ere eskertzen ditut. Lan hau 2018. urtean zurtz utzi gaituen aita Junes Casenave-Harigileri eskainia da.

Jasotze data: 2018/08/21. Behin-behineko onartze data: 2018/10/17. Behin betiko onartze data: 2018/12/28. 


\section{LABURPENA}

Mende luzetako ukipen azkarraren ondorioz, euskarak morfema sorta bat mailegatu die latinari eta inguruko erromantzeei. - $o /-a$ bukaeren araberako pareen mailegatzearekin barietate batzuek inflexiozko generoaren hastapenak garatu dituzten bezala, -sa atzizkiarekin ekialdeko euskara eratorpenezko genero bereizkuntzan abiatu da. Zuberoako euskara historikoaren corpusean funtsaturik, lan honen xedea da -sa-ren agerpen historikoa aztertzea eta iruzkintzea. Horrezaz landara, eta Euskaltzaindiak bide hori baztertu badu ere, egungo ekialdeko anitz euskaldunen artean -sa atzizkiak duen emankortasuna ilustratuko dugu.

Gako hitzak: ekialdeko euskara; mailegatze morfologikoa; genero gramatikala; eratorpena; - sa atzizkia.

\section{RESUMEN}

Como consecuencia de la prolongada situación de contacto lingüístico, el vascuence ha tomado préstamos morfológicos del latín y de las lenguas romances. Así como a partir del préstamo de pares acabados en $-o$ y $-a$ algunas variedades vascas han adquirido una incipiente distinción de género de tipo flexivo, con el sufijo -sa el euskara oriental se ha adentrado en una distinción de tipo derivacional. Basándonos en un corpus del suletino histórico, en este trabajo examinamos la atestiguación y el uso del morfema -sa. Además, mostraremos que para muchos hablantes de dialectos orientales el sufijo -sa mantiene su vigor como morfema productivo, pese a que la Real Academia de la Lengua Vasca lo haya desaconsejado.

Palabras clave: euskera oriental; préstamo morfológico; género gramatical; derivación; sufijo -sa.

\section{ABSTRACT}

Due to the long-term situation of intensive contact, Basque has borrowed a number of morphemes from Latin and Romance languages. Whilst certain varieties show an incipient inflectional distinction of gender as a result of the borrowing of lexical pairs ended in $-o /-a$, Eastern Basque has to a certain extent acquired a derivational gender distinction by means of the Romance-origin suffix $-s a$. Based on a corpus of historical Souletin, in this paper we analyse the occurrences of the morpheme $-s a$. Moreover, we will show that present-day Eastern Basque speakers continue to use $-s a$ as a productive suffix, despite the fact that the Royal Academy of the Basque Language has advised against it.

Keywords: Eastern Basque; morphological borrowing; grammatical gender; derivation; -sa suffix. 
1. Sarrera. 2. Mailegatze morfologikoaz. 3. Mailegatzea, genero gramaTIKALAREN ENBRIOI. 3.1. Euskaraz, eratorbide zein inflexio mailetan. 3.2. So bat euskaratik kanpo. 4. ZUBEROAKO TESTUEN LEKUKOTZA (XVI.-XIX. MENDEAK). 5. OEHREN TESTIGANTZA. 6. ERATORPEN ARAUAK ETA SEMANTIKA. 6.1. -sa har dezaketenak. 6.2. -sa-dun izenetarik eratorriak. 6.3. Semantikaz bi hitz. 7. -SA ATZIZKIAREN HALA-MODUZKO ESTATUSAZ. 8. -SA MORFEMA, ORAINO EMANKOR. 9. ONDORIOAK. 10. ERREFERENTZIAK.

\section{SARRERA}

Onartua da euskarak ez duela genero gramatikalik, bederen izenez ari bagara; halere, deklinabidean izen bizidunek eta bizigabeek portaera diferentea dute -ezaguna da, halaber, aditz morfologian badela generoaren araberako markatzea, molde alokutiboari lotua-. Izen sintagman bereizkuntza morfologikorik ez den arren, historikoki euskalki gehienek -ez bada guztiek- hainbat paretan maskulino/femenino bereizi dute, besteren artean $-s a$ atzizkiaren edo gaztelaniari mailegatutako $-o /-a$ oposizioaren bidez.

-sa atzizkia egoera konplexu batean kausitzen da. Alde batetik, iritzi garbizaleenentzat euskal gramatikari zein hiztunen senari arrotz litzateke, eta beraz haren mailegatzeak ez luke zentzurik. Beste aldetik, zenbait hiztun eta arauemailek hizkuntzaren usadio sexistekin lotzen dute -sa atzizkia ( $c f r$. Davant, 2006). Horren ondorioz, euskara batuan atzizkia baztertu, edo bederen aski mugatu dute (Euskaltzaindia, 1991, 36. orr.). Testu zaharrak, aldiz, erabilpen zabalago baten lekuko dira. Paraleloan, batzuek baztertu nahi duten -sa morfemak babeslekua atzeman du azken hamarkadetako $\mathrm{Zu}$ beroan. Nonbait, gau eskolako irakaslesak, herri etxeko idazkarisak eta are errugbi taldearen züportersak kolore bat ematen diote euskarari, hots, zuberotartasunarena (Maider Bedaxagar eta Argitxu Camus, bekoz beko). Halako formak pürki xiberotar hautemanak izateak -sa atzizkiaren emankortasun berri batera bulkatu duke.

Morfologiaren mailegatzeari dagozkion kontzeptu batzuetatik abiaturik ( $\mathbb{2}$ ), lan honetan euskarak zenbait morfemaren bidez garatu dituen genero bereizkuntzaren hasikinen kontu errendatuko dugu, -o/-a oposizioari arta berezia emanez $(\mathbb{S} 3.1)$ eta munduko hizkuntzetan gertatzen denari begiratuz $(\mathbb{S} 3.2)$. Testuetan sartuz, -sa atzizkiaren 
agerpena bilduko dugu, lehenik zuberera historikoaren lekukotzarekin $(\mathbb{S} 4)$, eta gero OEHk ematen duen informazioarekin $(\mathbb{S} 5)$. Ondoan, -sa atzizkiaren eratorpen ereduak eta ñabardura semantikoak aipatuko dira $(\mathbb{S} 6)$. Haren hala-moduzko estatusaz aritu ondoan $(\mathbb{S} 7)$, -sa morfemaren egungo irautearen testigantza ekarriko dugu $(\mathbb{S} 8)$, ondorio batera etortzeko $(\mathbb{9} 9)$.

\section{MAILEGATZE MORFOLOGIKOAZ}

Mailegatzea eta hitz elkarketarekin batera, eratorpena da hizkuntzek hitz sorkuntzarako dituzten bide nagusietarik bat; bestelako baliabiderik ere bada, hala nola akronimoak, zabalkuntza semantikoa eta berrezarpen lexikala. Oro har, bi mailegatze mota bereiz daiteke: lehenbizikoan hizkuntza emailearen elementu baten materia fonologiko zein forma morfologikoa mailegatzen da (matter, labur «MAT-borrowing»), eta bigarrenean elementu baten eredu funtzional eta semantikoa kopiatzen da (pattern, "PAT-borrowing», maiz kalko deitua) (Sakel, 2007).

Bestalde, eztabaidatu izan da hizkuntzaren zein elementu mailega daitekeen aiseago ala nekezago. Hortaz, mailegagarritasun eskalak proposatu izan dira (ikus Thomason \& Kaufman, 1988, 74-76. orr.; Field, 2002, 36-37. orr. eta Matras, 2007 \& 2009, 153-165. orr.), bakan batzuk baizik ez aipatzeko. Morfologia, oro har, eskala horietako urrats gorenetan kokatzen da, hots, hizkuntzen arteko kontaktu indartsua denean mailegatzen ahal da. Eta morfologiaren barnean, eratorpenezko morfemak aiseago mailegatzen dira inflexiozkoak baino. Soilik ukipen bereziki estuko egoeretan inflexio morfemak ere mailegatzen dira: turkierarenak albanieran edo Anatoliako grekoan, eslavierarenak errumanieran edo ingelesarenak galesean (Gardani, 2008; ikus, halaber, Gardani, Arkadiev \& Amiridze, 2014 eta Seifart, 2013). Desberdintasun tipologikoek zailago errendatzen badute ere, euskarak inflexio morfemarik ere mailegatu du, adibidez mendebaldeko mintzoetan sartuxea den -o/- $a$ bukaeren parea (ikus $\mathbb{3}$ 3.1). Morfologiari doakionean, materiaren eta ereduen mailegatzea, biak gerta daitezke eratorpen zein inflexio morfemekin.

Eratorbideaz denaz bezainbatean, komeni da bi puntu gogoratzea. Lehenik, euskara historikoa hizkuntza atzizkizalea da: aski da atzizkien zerrenda luzeari eta aurrizki bakanei soño bat egitea haien artean dagoen desoreka handiaz ohartzeko, eta hori sov hizkuntza izaerarekin lotu behar da. Bigarrenik, euskarak eratorpen morfemak mailegatu dizkie erdarei, seguruenik Azkuek onartutako alien solteak baino gehiago ${ }^{1}$. Kontrakoa

1 «Sufijos alienígenas. No es extraño que entre los cuatro centenares mal contados de prefijos, infijos y sufijos que contiene nuestra lengua se hayan deslizado algunos de procedencia exótica» (Azkue, 1923, 21-22. orr.). Hona Azkueren (1923, 22-23. orr.) zerrenda: -ada (gogortada), -ade (gogortade), -ate (libertate) -hiru hauek alomorfo gisara ematen ditu-, -aje (adaje), -aire (gorriaire), arra- (arramaiatz), -ero (zurrutero), -ezia (agudezia), -ler (ostaler), -antza (ustantza), -sa (artzaintsa), -oso (triposo), -ura (hedadura), -zio (asmazio) \& -tu (garbitu); Azkuek -ari \& -tasun ere aipatzen ditu, nahiz haien jatortasuna argudiatuko duela dioen. Geroztik, Mitxelenak (1957, 145. orr; 1974, 191. orr.), besteak beste, -ari latinaren -ari(um) bukaeratik datorrela sustengatu zuen, eta De Rijkek (1991) -pen atzizkia -men(du) mailegatutik datorrela. Berrikiago, Buenok (2011) erakutsi du zenbatenaz testua zaharrago, hainbatenaz atzizki mailegatu gehiago direla; Larramendik aldatuko zuen joera hori behin betiko (cfr. Urgell, 2004). 
harrigarria litzateke, euskara gutxienez azken bi mila urteetan ukipen azkarrean egon delako, lehen latinarekin, eta gero inguruko erromantzeekin. Hortaz, euskarak nekez mailegatu du aurrizkirik (des- edo erre-), baina latinaren eta erromantzeen atzizkiak aise sartu dira hizkuntzan; ezagunenak aipatzeko, hor ditugu -mendu, -zio, -dura, -eria edo -tate.

Euskara eta inguruko hizkuntzen arteko harremanei ikuspegi zabalago batetik so eginez gero, ukipen bereziki azkarra izan delako ideia berresten da. Munduko hizkuntzetan afixu mailegatuak biltzen dituen datu-basearen zifrak (Seifart, 2013) aski adierazgarriak dira. Bilduma horrek bere baitan hartzen dituen ehun hizkuntzen artean -eta kontuan hartzen dituen edo ez dituen morfemen kopurua gorabehera- soilik bik mailegatu dute euskarak bezainbeste afixu (35) edo gehiago: arawak familiako resígaro hizkuntzak (50 afixu bora hizkuntzatik) eta megleno-errumanierak (35 afixu bulgarieratik). Halaber, zerrenda horretan ez dira anitz beste hizkuntza bati hamarretik goiti morfema mailegatu diotenak ${ }^{2}$.

Ezinbestean, morfema baten mailegatzea morfema hori duten hitzen mailegatzetik pasatzen da (cfr. Lindsay \& Aronoff, 2013); horren adigarria da gure erdaretan begien bistan bertakotzen ari den ingelesaren -ing atzizkia (esp. vending, fr. filting). Euskararen eta gaskoiaren arteko ukipen azkarrari begira, 1. taulak bi hizkuntzek komun dituzten hainbat bukaera zerrendatzen du, morfema izan ala ez, eta diakroniaren geruzak edo morfemen hedadura zehaztu gabe (Coyos, 2008, 929-933. orr.); ikusten denez, bearnesaren bukaera horiek guztiak ez dira euskararen morfema bihurtu, baina guztiak existitzen dira Zuberoan, mailegu andana batean. Hortaz, soilik bukaera (edo hasiera) horiek euskal oinei eransgarri suertatzen direlarik erran dezakegu Zuberoako euskarak bearnesaren -batzuetan erromantze zaharragoaren- morfemak mailegatu dituela, «MAT-borrowing» delakoan: -ant (tratülant), -er (gezürter), -aje (mintzaje), -ada (abiada), -us (handius), -üra (herstüra), -ot (zaharrot) edo des-(desegin). Coyosen zerrendatik kanpo bada gehiagorik: hor ditugu -sa atzizkia edo arra- aurrizkia.

2 Albanieraren aldaera den arvanitikak grezierari (31), sebjan-küöl èven tungusiar hizkuntzak jakuterari (22), girindji kreolerak pama-ñunga familiakoa den girindji hizkuntzari (19); indonesierak sanskritoari (18), khantiera uraldarrak komi-zyrian hizkuntza uraldarrari (15), medny aleuterak errusierari (15), indo-iraniar familiako assamerak tibetar-birmaniar taldeari (15), albanierak serbokroazierari (14), jakuterak mongolierari (14), indonesierak nederlanderari (13), kaxmirerak pertsierari (13), yiddishak errusierari (13), marierak -uraldarra-txuvaxera turkiar hizkuntzari (12), ipar tajikerak uzbekerari (11), kalderash-romani hizkuntzak errumanierari (11) eta azerbaijanerak pertsierari (10). 
1. taula. Latin, bearnes eta egungo zubereraren arteko zenbait korrespondentzia ${ }^{3}$

\begin{tabular}{|c|c|c|}
\hline Latina & Bearnesa & Zuberera \\
\hline -älem & -au (espitau) & -ale (ospitale) \\
\hline -ante & -ant, -dant, -lant (franchimand) & -ant (tratülant, ogendant) \\
\hline -ärǐum, -ārǐam & -èr, -èra (cautèr, menusèr) & -er (kauter, menüser, gezürter) \\
\hline -ätǐcum, -ätǐcam & -atge, -atja (coratge, viatge) & -aje (kuraje, mintzaje) \\
\hline -ätiōne & - ason $>-$ as $\tilde{u}$ & $(\operatorname{arrazu} \ldots)$ \\
\hline$-\bar{a} t u,-\bar{a} t a$ & $-a t,-a d a$ & (buhada, phausada, taulada) \\
\hline -éllum, -èllam & -eth, -èra (manteth, pasteth...) & (pasteth) \\
\hline -ènse & -és, -esa & (baiones, frantses) \\
\hline -ent & -ente, -enta (pendent, regent) & (pendent, errejent) \\
\hline$-\bar{i} n u,-\bar{i} n a$ & $-i n,-i n a$ & (koki, bedezi) \\
\hline$-\overline{o s u},-\overline{o s} a$ & -ós, -osa & -us (irus, malerus, handius) \\
\hline -tōrǐum, -tōrǐam & -der, -dera (bohader, eishugader) & -er (buhader, txükader) \\
\hline$-\bar{u} r a$ & -ura (frescura) & -üra (arrenküra, herstüra) \\
\hline$-\bar{u} t u,-\bar{u} t a$ & $-u t,-u d a($ perdut, perduda) & (pergüt) \\
\hline -ottu, -otta & -òt, -òta (coquinòt, plaçòta) & -ot (plaxot, tripot, haurrot) \\
\hline dis- & des- & des-(desobedient, desegin) \\
\hline male- & mal- & (malestrük) \\
\hline
\end{tabular}

\section{MAILEGATZEA, GENERO GRAMATIKALAREN ENBRIOI}

\subsection{Euskaraz, eratorbide zein inflexio mailetan}

Aspaldidanik, euskarak maskulino/femenino generoen araberako hitz pareak mailegatu dizkie inguruko erromantzeei. Ekialdeko mintzoetan gaskoiaren -erl-èra saileko pareak sartu ziren (koziner/kozinera), bai eta bestelakoak ere (bastart/bastarda, pandard/pandarda, kokĩlkokina, fripülfripuna). Lafonek (1947, 263. orr.) balio femeninozko - $\tilde{n} a$ atzizkia aipatzen du: astaña «anesse ; femme sotte»; Azkuek (1905, s.v. - $\tilde{n} a)$ Zuberoan, Erronkaribarren eta Zaraitzun kokatzen zuen, - $\tilde{n} o$ diminutiboari lotuz.

Erabiliago eta hedatuagoa dugu -sa atzizkia, ogibide, funtzio edo egoera soziala adierazten duten izen multzo batean: laborarisa "paysanne», okhintsa «boulangère» edo alharguntsa «veuve» (Lafon, 1947, 263. orr.). Atzizki honen jatorria berriz ere erromantzeei mailegatutako hitz pareetan datza: printzelprintzesa, dukeldukesa, kondel kondesa, eta abar. Lafonek seinalatzen duenez, mailegua ez bide da arras goiztiarra, zeren bestela txistukari bizkarkariaz sartu baitzatekeen $\left({ }^{*}-z a\right.$ eta ez $\left.-s a\right)$. Haasek (1992, 50. orr.), eta harekin Eliassonek (2013, 279. orr.), preseski seinalatzen dute gaskoi hizkuntza emaile bezala. Printzelprintzesa bezalakoen eraginaz, hiztunek -essa $\rightarrow-s a$

3 Coyosen (2008, 929-933. orr.) zerrendatik moldatua. 
berranalisia eginen zuten, -sa izen femeninoen marka gisara interpretatuz. Datatzeko zail den memento batetik aitzina -menturaz Erdi Aroaren azken partean-, -sa akabantza aipatutako maileguetarik euskal erro zenbaitetara iragan zatekeen, atzizki izaera bereganatuz. Reguerok -sa atzizkiaren erabilera goiztiarraren zantzuak ikusten ditu Nafarroan:

Erdi Aroan, oso zalantzazkoak izan arren, -sa atzizkiaren erabileraren aztarnak aurkitu ditugu. [...] Honatx adibideok: Arceyca eta Maytessa, biak 1366 urtean. Arceica $<$ *artzai + sa izan liteke eta onargarri dirudi, emakume bati egiten baitio erreferentzia: Arceyca llamada Oneca. Alabaina txistukari bizkarkaria da, ez apikaria. Bigarren kasuak zalantza gehiago eragiten digu. Maytessa < *maite + sa izan litekeen arren, gizonezko bati egiten dio erreferentzia: Miguel Periz Maytessa. Beharbada atzizki femenino bera izan dezakegu Ortissa de Enassurieta (SJuan, 1230) antroponimoan ere ${ }^{4}$ (Reguero, 2012, 134-135. orr.).

Eratorpenezko morfemez harago, mendebaldeko mintzoetan ${ }^{5}$ ezaguna den -o/- $a$ bukaeren araberako genero bereizkuntza aipatu behar da. Lehenbiziko herexak Erdi Aroko datu onomastikoetan aurkitzen dira:

Pero la función de determinar el sexo de un nombre recaía en buena parte sobre los sufijos: -co se reserva para los masculinos (Bellaco, Enneco, Vitaco, etc.) y -ca para los femeninos (Onneca, Urraca), lo mismo que -nda (Ochanda). La terminación -a se empleaba para caracterizar nombres de mujer, y podemos pensar que su empleo fue extendiéndose con el tiempo, como puede verse por los ejemplos citados y por casos como Semeno / Semena, por más que, en sí, no bastara para determinar el género: Urdina fem., pero Belagga, Garsea, etc., masculinos (Mitxelena, 1954, 429. orr.).

Eztabaidatu izan da Erdi Aroko onomastikan ageri den -o artikulu denetz (ikus Manterola, 2015, 244-246. orr.). Gure gustuko, afera trenkatua da: datuen analisi sistematikoa egin ondoren, Manterolak hauxe ondorioztatu du: «-a duten izengoitiek gizonezkoak zein emakumezkoak izenda ditzakete, baina -o dutenak gizonezko izenetan baizik ez dira agertzen, salbuespenik gabe»; egitate horri argudio sendoak gaineratzen dizkio. XVI. mendeko testuetan - $a$-o oposizioa ageri da, beharbada aiseago eremu erromantzatueneko lekukotasunetan, Landuchio («bruxa xorguina» eta «bruxo xorguinoa», apud Manterola, 2015, 246. orr.) eta Lazarraga lekuko (çu laco donzella bat ain lindaric 1186r, baina [seme bat] gazte lindo cortes curiosoa 1154r); halere ikus 4. oharra.

4 Arceyca formaren irakurketa 'artzeisa' izatera, artzaintsa (ustezko) modernoaren lehenbiziko agerraldia XIV. mendera aitzinatu beharko genuke. Bestalde, Maytessa gizonezko baten izenean aurkitzea korapilatsuagoa izan arren, deituraren sorburua emazteki batengan izateak azal lezake. Bi hauei Reguerok Ursoxa forma gaineratzen die; honen arazoa toponimoa izatean datza, vallis quae Ursoxa dicitur (García de Cortazar et al., 1979: 71 apud Reguero, 2012). Beste aukera da -ka irakurtzea, eta horrela Arceyca Erdi Aroko beste zenbait emazte izeni pareka lekieke: «Los nombres de mujer en - $c a$ se pueden considerar como el resultado de la moción de -co (Onneca, Urraca) y acaso sean equivalentes a aquitano Sunducca por ejemplo» (Mitxelena, 1954, 442. orr.).

5 Eta ez bakarrik mendebaldean. Jada Leizarragak sposo/sposa, adulteroàcladulteràc bezalako pareak eman zituen. Bestalde, Etxeparek advocatu (I 294) / advocata (I 392) parea baliatu zuen, bai eta thesorera (I 405) eta captiva (IV 2) forma femeninoak. Egun ere ere aurki daiteke horrelako parerik, adibidez muñuño/muñuña. 
Ez da harritzekoa, beraz, egun mendebaldeko mintzoetan -o/-a oposizioak bizirik irautea, guapolguapa, lixto/lixta, tipoltipa moldeko maileguak komunzki baliatzen baitira. Gehiago dena: Hualdek, Elordietak \& Elordietak (1994, 109. orr.) markatu dutenez, halako pare mailegatuek inflexio mailako genero bereizkuntzaren hasikin bat ekarri dute, -o/- $a$ bukaerak euskal erro zenbaitetara hedatu baitira. Mailegu andanaz harago, Lekeitioko euskaran gixajo/gixaja, sorristo/sorrista edo txotxolo/txotxola bildu dituzte Elordieta \& Elordieta, 1994, 109. orr. Lehenago Azkuek (1923, $\mathbb{S} 293$ ) mamelo «homme adroit, rusé» / mamela jaso zuen. Bergarako euskaran honako pareen forma femeninoak lekukotu dira: kokololkokola, memelo/memela (eta mamala), mokololmokola «bobo, insustancial", mozolo/mozola 'ergel' edo potxolo/potxola (Elexpuru, apud OEH). Zerrenda emenda daiteke: ijito/ijita (egileak Gasteizen entzuna), xurro/xurra ( $\leftarrow$ zuhur 'zikoitz'; Borja Ariztimuñoren komunikazioa) edo zoro/zora (Oxel Uribe-Etxebarriak Debagoienean entzuna). Datuak ikusirik, eta bereziki inolako hiztegitan oraino jaso gabe, baina gazteen ahotatik zirkulatzen hasiak direnak, erran daiteke -o/- $a$ oposizioa emankorra dela.

Badu garrantzia -o/- $a$ bukaeren araberako bereizkuntzak, zeren eta inflexio morfemak mailegatzeko zailen gertatzen diren hizkuntza elementuetakoak baitira (Comrie, 2008). Ezaugarri horretaz deskribatu dena honela laburbil daiteke: 1) -o/-a moldeko maileguak izenak ala izenondoak izan daitezkeen arren, oposizio hori euskal hitzetara hedatzean soilik izenondoetan ageri da; 2) genero bereizkuntza hau soilik gizakiei erreferentzia egiten dien pareetan da posible; 3) - a bukaera markatua da femeninoarentzat; eta 4) genero bereizkuntza izenondoetatik eratortzen diren aditz batzuetara heda daiteke (morenotu/morenatu, majotu/majatu), hizkuntza emailean ezinezkoa dena (Hualde, Elordieta \& Elordieta, 1994, 108-109. orr.). Gaia hetsiz, bihoa Eliassonen (2012, 279. orr.) ondorioa: «Romance gender inflection has intruded into Basque, albeit only marginally, in some dialect areas. Most importantly, from the point of view of copiability, we observe that the gender distinction in the donor languages is semantically and morphologically transparent and that Basque provides no absolute structural blockage to a gender distinction in adjectives».

\subsection{So bat euskaratik kanpo}

Ikuspegi tipologikotik, gutxi dira genero morfemarik mailegatu duten hizkuntzak; Seifarten (2013) datu-basean ehunetarik sei dira -euskara barne-, guztiak ukipen azkarreko egoeran ${ }^{6}$. Mailegatze morfologikoaren ondorioak denaz bezainbatean, ohartarazi behar da genero gramatikalik ez zuten hizkuntza batzuek ezaugarri hori garatu dutela ukipen egoera baten ondorioz. Horrelakoa da tagalo, ilokano edo txamorro hizkuntzen

6 Arawak familiako resígaro hizkuntzak genero markatzen duten bi morfema mailegatu dizkio bora hizkuntzari: - $d_{3}$ 'femenino singular' (Banaa?dzé 'koinataren ahizpa edo koinatuaren arreba') eta -pidze ( $p^{\text {haipidzé }}$ 'atso'). Zipreko arabierak generoa lotutako lau inflexio morfema hartu ditu grekeratik: $-i$ 'maskulino singular', -kkya 'maskulino plural', - a 'femenino singular' eta -úes 'femenino plural'. Kurux hizkuntza drabidikoak femeninoa adierazten duen morfema bat mailegatu dioke hindiari. Yiddishak izen femeninoak eratortzen dituzten hiru atzizki hartu dizkio errusierari: - ke 'femenino' (lérerke 'irakaslesa'), -ixe 'animaliaren eme / jendeizenen femenino peioratibo' (léjbixe 'lehoisa' edo 'Leyben emaztea') eta -ńitse 'pertsonaltze edo izen agentiboetako forma' (ejšes-iš-nítse 'adultero.FEM'). Orobat, gizakien femeninoaren adierazteko suomierak bi eratorpen atzizki mailegatu dizkio suedierari: -inna (tohtorinna 'mediku.FEM') eta -ska (seppäskä 'jostunaren emaztea'). 
kasua, aldaketa gaztelaniak eragin baitu (Iván Igartuaren jakinarazpena). Beraz, noizbait -o/-a moldeko pareak orokor balitez, euskara zerrenda horretan sartzeko liteke.

Estonierak ez du genero gramatikalik, baina eratorbidera jotzen du izen batzuen forma femeninoen eratortzeko, euskarak -sa morfemarekin garatu duen estrategia berarekin. 2. taulak estonierak dituen pare lexiko bakanetakoak biltzen ditu; erremarka bedi -annal-inna atzizkia ez duten forma femeninoak mailegatuak direla, edo bestelako erabide baten ondorio. Estonieraren ahizpa den suomierak -tar atzizkia baliatzen du antzeko kasuetan: kuningatar 'erregina', jumalatar 'jainkosa', herttuatar 'dukesa' $\leftarrow$ kuningas, jumal, herttua). Ez da gure xedea atzizki horien etorkiaz aritzea; halere, beroiek hartzen dituzten izenei so egitea aski da euskararekiko paralelotasunaz ohartzeko.

2. taula. Estonieraz genero bereizkuntza duten zenbait bikote lexiko

\begin{tabular}{|l|l|}
\hline kuningas 'errege' & kuninganna 'erregina' \\
\hline jumal 'jainko' & jumalanna 'jainkosa' \\
\hline mü̈̈ja 'saltzaile' & mü̈̈janna 'saltzaile (fem)' \\
\hline preester 'apaiz' & preestrinna 'apaiz (fem)' \\
\hline herstog 'duke' & herstoginna 'dukesa' \\
\hline parun 'baron' & paruness 'baronesa' \\
\hline direktor & direktriss \\
\hline luuletaja 'poeta' & luuletajalpoetess 'poeta (fem)' \\
\hline opetaja 'errejent' & näisõpetaja 'errejentsa' (cfr. naine 'emakume') \\
\hline
\end{tabular}

\section{ZUBEROAKO TESTUEN LEKUKOTZA (XVI. - XIX. MENDEAK) ${ }^{7}$}

Oro har, zenbatenaz ekialderago, euskal hiztunek hainbatenaz modu sistematikoagoan erabiltzen dute -sa atzizkia (Trask, 2003, 117. orr.). Hortaz, ez da harritzekoa Zuberoan testu zaharrenetarik -sa atzizkidunik aurkitzea ${ }^{8}$. Tartas lehenbizikoa da, honakoak lekukotuz: avocatussa (Onsa 173), bekhatoria eta bekhatoressa (Onsa 12), bekhatoriari eta bekhatoressari (Onsa 22), bekhatoriac eta bekhatoressac (Onsa 100)

7 Lan honetako testu aipamenak OEHren laburduren sistemaren araberakoak dira. Baliatu zaigun corpusa XVI.-XIX. mendeetako testuez osatua da: Lç (hiztegiñoa), O Pro, Bela, Saug, O Po, Tt Onsa, Tt Arima, PSing, Bp, CatOlo, Othoitz, Mst, IP, Ressegue, StJul, Mercy, Egiat I, Edipa, Xarlem, DKhirist, UskLi, Khurutch, Meditacioniac, Ip KurBD, Etchahun, Arch Fab, MaiMarHil, Ip Dial, Myst, CatS, EvS, Epit eta SGrat. Ondokoak OEHren corpusetik kanpo daude: Etxart = Erronkari eta Zuberoaren arteko gutuneria ofiziala (1616), NLilia $=$ Noelen lilia composaturic huscarez (Paue, 1782), SteEli = Sainte Elisabeth de Portugal (Eskiula, 1750), DKhirist = Doctrina khiristia haurren instruccionetaco, idequiric hitcez hitz Franciaco eliza ororen usageco catichimati (Baiona, 1812) eta HOrdre = Heren-ordreco escu-libria igante bestetaco officio berrieki (Oloroe, 1860). Bestalde, Urkizuk editatu xaribariak (Urkizu, 1998) antzerki bakoitzaren izenburuaz aipatuko ditugu, dagozkien bertseten zenbakiekin; hauexek dira: Bala eta Bilota, Boubane eta Chiloberde, Malqu eta Malqulina, Pierris eta Catiche, Planta eta Eleonora \& Saturna eta Venus. Finitzeko, Baküs fartsa ere miatu dugu (Mozos, 1986).

8 XV. mendeko Zuberoako euskararen informazio onomastikoa ematen duen Censier gothique de Soule delakoan ez da -sa atzizkiaren agerraldirik; gehienez Barkoxeko Ostau d'Abadesse oikonimo erromantzea aipa liteke (1: IV). 
\& Ordian duqueçu arima burçaguissa, eta gorpitça nescato (Arima 85). Belapeirek arartecossa (I 150), confrai confraissec (I 147) eta profetessa (II 105); ohart bedi Belapeirerentzat alhargun bali dela emazteentako: Santa Anna alhargun perestu, Profetessa, eta barour eguilé handia (II 105) -izan ere, alharguntsa formaren lehen agerraldia 1793 koa dateke-. 1706koa den Oloroeko katiximan buruçaguisa soila ageri da (10), eta Maisterrengan burçaguissa (III 55, 6).

Eskiulan datatuak diren itzulpenei doakienean, Resseguek konfraisa du: confray eta confrä̈sec (5) \& confray eta confraïsser (6). Mercyk avocatussa (2), confrayssa (dozena bat aldiz) eta sacristainsa (36) dakartza, beherago aipatua den erran-nahiaz ( $\$$ 6.3). Eskiulan datatua da, halaber, Sainte Elisabeth de Portugal trajeria (1750), agian -sa moldeko formen lekuko oparoena: arartekossa (1002), buruçaguissa (318, 323 \& 1225), guiharrabassa 'amaginarreba' (1248, 1253 \& 1275; maskulinoan guiharreba 174), ostatussa (227) eta protetorssa (1313). Azpimarratu behar da giharrabasa 'amaginarreba' ez dela beste testuetan aurkitzen (salbu Gèzeren hiztegian), eta protetorssa hapax absolutua dela. Hori ez ezik, Sainte Elisabeth-en genero bereizkuntzaren ondoriozko formetarik eratorriak ere ageri dira: alhargüntsatü, erregiñatü 'erregina bilakatu' eta

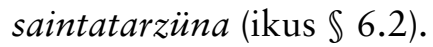

Herri antzertian, beraz, ez da arraroa -sa-dunik ediretea. 1770ekoa den Saint Julien d'Antioche trajeriak buruçaguissa (1013) eta arartecossa (436) lekukotzen ditu, Edipa pastoralak (1793) alhargunxa (310) hitzaren lehen agerraldia, eta Charlemagnek (ca. 1800) paganosa hapaxa (1074). Astolasterrek bügresa, deabrüsa edo diablesa lekukotzen dituzte (ikus aitzinago), ohiko alhargüntsaz edo bür(ü)zagisaz gain. Planta eta Eleanora xaribariak laborarisa (4) formaren lehen agerraldia dakarke -antzerkiaren datazioa ez da batere zehatza-, eta Saturna eta Venus-ek ostatüsa bakana (326).

1785ean Egiategiren lehen liburuak aizosa 'auzo.FEM' hapaxa ematen du (I 30), artzaintsa formaren lehen agerraldia (I 14), gehi bürüzagisa (5 agerraldi). Azkenik, XIX. mendeko erlijio testuek -sa atzizkidun formen erabilera moderatuagoa erakusten dukete. Alhargüntsa eta bür(ü)zagisa ohikoetarik landa, mende hastapeneko Uscara libriak arartecarissa (62) hapaxa dakar, eta 1860koa den Heren-Ordreco escu libriak artçainxa (35). -sa atzizkiaz harago, zenbaitetan hau bezalako pasarteak aurkitzen ahal ditugu: Sainta Elisabeth Hongriacoua, alhargunxa; Heren Ordreco emazten patrouna. (HOrdre 40-41), non Sainta, alhargunxa eta patrouna forma femeninoak baitira.

Ondoko zerrendako forma batzuk Zuberoan baizik ez dira lekukotu: abokatüsa, arartekosa, bügresa, bürüzagisa († 1860), konfraisa († 1780) eta ostatüsa. Beste batzuk hapax legomena dira, Zuberoako testu batean edo bestean atzemanak: aizosa, arartekarisa, giharrebasa, paganosa, protetorsa eta sakristainsa.

- AbOKaTÜSA (Tt Onsa 173; Mercy $21 \& 30$ ).

- Aizosa (Egiat I 30). 
- Alhargüntsa (Edipa 310; Malqu 386 \& 407; Saturna 163; UskLi 227; Meditacioniac 217; Archu 40; MaiMarHil 120; HOrdre 33, 35 (2), 36, 37 (3), 39 (2), 40).

- ARARTEKARISA (UskLi 62).

- arartekosa (Bp I 150; StJul 436; SteEli 1002).

- $\quad$ ARTZAINTSA (Egiat I, XIV; HOrdre 35).

- bekatoresa (Tt Onsa $(12,22 \& 100)$.

- BÜGReSA (Bala 16, 25 \& 27; Pierris 67 \& 120; Planta 96, 102 \& 105; Saturna 70, 94 \& 149; Malqu 355).

- BÜr(Ü)Zagisa (Tt Arima 85; Bp I 23 \& 27; CatOlo 10; Mst III 55, 6; StJul 1013; Egiat I (5); SteEli 318, 323 \& 1225; Malqu 245 \& 328; Boubane 53, 103 \& 158; Meditacioniac 194; HOrdre 61, 72 \& 83).

- DEABRÜSA (Malqu 197 \& 222).

- diablesa (Bala $19 \& 20)$.

- GERRIERSA (Baküs 52).

- giharRabasa (SteEli 1248, 1253 \& 1275).

- $\quad$ KOnfraisa (Bp I 147; Ressegue 5 \& 6; Mercy 5, 6 (2), 7 (4), 8, 35 \& 38 (2)).

- Laborarisa (Planta 4).

- OSTATÜSa (SteEli 227; Saturna 326).

- Paganosa (Xarlem 1074).

- PRINTZESA (Tt Onsa (2) \& Arima (41); Egiat I (2); Othoitz 69; StJul 107 (2); Edipa 20 \& 597; Xarlem 9, 118 \& 142; SteEli 16).

- PROFETESA (Bp II 105; Ip 1854).

- $\quad$ PRotetorsa (SteEli 1313-1314).

- SAKRISTAINSA (Mercy 36).

Bistan denez, -sa-dun formen kideak ere kontuan izan behar dira. Kasu batentzat, arartekarilarartekarisa (arartekolarartekosa) parea ez da sistematikoki erabilia izan, hainbat testutan arartekari, ararteko formak ez-markatuak izanik. Ama Birjinari erre- 
ferentzia egiten dioten agerraldi guztiak bildu ondoan, forma ez-markatua ondoko testuetan ageri da: $1676 \mathrm{ko}$ pronoa (Ararteco eçarten deriocielaric Virgina ama saintia; $\operatorname{PrS} 29$ ), 1782ko Noelen Lilia buscarez (Jesus-Christ[en] ama saintia Arartecary balia cite; NLilia 14), Inperioaren katixima (Dezagun othoi Maria Virgina dohaxia arartecari cerbutcha daquigun Gincouaren eretcian; DKhi 9), 1844ko meditazioneak (Virgina eta Alhargunxac oro, hounen arartecari içan citeye; Meditacioniac 217), 1852ko Maiatza edo Mariaren Hilabetia (Ama dukiana arartecari salbaturen du semiac; MaiMarHil 15, gehi 16, 22, $99 \&$ 107) eta 1860ko Heren-Ordreko escu librian (arartecari photerexia; HOrdre 83). Belapeirek arartecari (I 147) zein arartecossa (I 150) baliatzen ditu, eta beste hiru testutan femenino markatuko formak ageri dira: arartekosa (St)ul 436; SteEli 1002) eta arartecarissa (UskLi 62). 3. taulak aipatu formek emeari lotuak dituzten agerraldiak biltzen ditu.

3. taula. Arartekolarartekosa \& arartekarilarartekarisa: forma markatua eta ez-markatua femeninoan

\begin{tabular}{|l|c|c|c|c|} 
& ararteko & arartekosa & arartekari & arartekarisa \\
\hline PrS 1676 & 1 & - & - & - \\
\hline Bp 1696 & - & 1 & 1 & - \\
\hline StJul 1770 & - & 1 & - & - \\
\hline NLilia 1782 & - & - & 1 & - \\
\hline UskLi post 1785 & - & - & - & 1 \\
\hline SteElica. 1805 & - & 1 & 1 & - \\
\hline DKhirist 1812 & - & - & 1 & - \\
\hline Meditacioniac 1844 & - & - & 5 & - \\
\hline MaiMarHil 1852 & - & - & 1 & - \\
\hline HOrdre 1860 & - & - & - \\
\hline
\end{tabular}

\section{OEHREN TESTIGANTZA}

ALARGUNTSA sarreran, OEHk -sa atzizkiaren jatorri eta orainarekiko aipuak uztartzen ditu: «Derivado con el suf. -sa (-tsa), de origen románico (cfr. jainkosa 'diosa', ya SP, seguramente cultismo), de uso sólo en el extremo (nord)oriental del País. Es reciente su extensión inmoderada a otras palabras». OEHk lautan hogeitik goiti -sa atzizkidun forma biltzen du sarrera gisara. Haien artean hango eta hemengo euskalkietakoak badira ere, Iparraldeko mintzoen nagusitasuna begien bistakoa da. Ondoan -sa-dun sarrera-buruak bildu ditugu: lehenik bere horretan mailegatu izan direnak (a), eta gero euskararen barneko eratorpenaren ondoriozkoak (b) -azpimarkaturik, gure corpusak ere lekukotzen dituenak-. Zerrendak ez du luzeegi iduri, baina testu zahar eta ez hain zaharretan aurkitzen dugunaren lekuko fidela da.

a) ABADESA, ARTXIDUKESA, BANPIRESA, BARONESA, BIZKONDESA, DIAKONISA, DUKESA, KAPITANESA, KONDESA, MAESTRESA, MARKESA, PRINTZESA, PRIORESA, PROFETESA, SAZERDOTISA, TIGRESA. 
b) ABOKATUSA, AlARGUNTSA, AMAginARrEBASA, AMORESA, ANDRESA, ARARTEKARISA, ARARTEKOSA, ARTZAIESA, ARTZAINTSA, ATEZAINTSA, AUZOSA, AZTISA, BARONTSA, BARTOLOMESA, BASURDESA, BATERONSA, BEKATORESA, BERTSOLARISA, BOLANJERSA, BOTIKARIOSA, BRIGANTSA, BUGRESA, BUHAMISA, BURUZAGISA, DANTZARISA, DEABRUSA, DIZIPULUSA, EGOILIARSA, EIHERAZAINTSA, EMAGINTSA, ENPERADORESA, ERIZAINTSA, ERRIENTSA, ESKOLIERSA, EUSKALDUNTSA, ETXETIARTSA, FIDELSA, GAIZTAGINTSA, GIZONTSA, HARGINESA, INFIRMIERTSA, JAINKOSA, JUDUSA, KANTINIERSA, KISKILSA, KOKINTSA, KOMEDIANTSA, KONFRAISA, KOZINERTSA, LABORARISA, LEHENESA, LEHOISA, MEDIKUSA, MIXKANDISA, NESKISA, OKINTSA, OSTALERTSA, OSTATESA, OSTATUSA, PAGANOSA, SAKRISTAUSA, [SAKRISTAINSA], SORGINTSA, TABERNARISA, TXIMINOSA, UGANDDERUSA, UMANTESA, ZALDUNTSA, ZAPATAGINESA.

Gure corpusak 83etarik 17 baizik ez du lekukotzen; ifrentzuan, Sainte Elisabeth de Portugal trajerian OEHk jaso gabeko bi forma bildu dugu: giharrebasa 'amaginarreba' (1248, 1253 \& 1275) \& protetorsa (1313); eta Baküs fartsan gerriersa (52). Horietaz gain Bala eta Bilota astolasterrean diablesa ageri da (cfr. bearn. diablesse), pertsonaia elebidun baten ahoan $(19 \& 20)^{9}$. Zubererarentzat bildu dugun corpusak XIX. mendean du akabantza, OEHk jasotako anitz-sa-dun forma berriagoak direlarik. Beraz, OEH XX. mendean gertatu den $-s a$ atzizkidunen emendatzearen isla bide da.

Datuen artean ez da komeni ahanztea Larramendi, betiere hizkuntzaren baliabideez oharturik, -sa atzizkiaz baliatu zela bere neologismo batzuen eratzeko. Horietakoak dira bateronsa 'erregina', lehenesa 'printzesa', ugandderusa 'naiade' edo umantesa 'emakume heroi'.

\section{ERATORPEN ARAUAK ETA SEMANTIKA}

\section{1. -sa har dezaketenak}

Errana dugu, -sa atzizkia partikularki lanbidea, funtzioa edo gizarte egoera adierazten duten izenei eransten zaie, baina ez bakarrik: herritargo izenkien femeninoen eratortzeko (xiberotarsa, mauletarsa) edo zenbait animaliaren emeen izendatzeko ere baliatu izan da -azken honetarako euskarak bide propioak ukan arren-: $b a-$ surdesa, lehoisa, tigresa, tximinosa (OEH, s.v.). Orain arte adibide guztiak bizidun emeenak izan baitira, Tartasen Ordian duqueçu arima burçaguissa, eta gorpitça nescato pasarteak (Arima 85) arreta merezi du, arima hitzak erromantzez duen genero

9 A diablesa flambesa / Et que mas getat / Lou toupin you crei / belein houradat! [= Ah, diablesse, flambesse ! / et tu m'as geté / le pot, je crois bien / Je l'ai percé] (Bala eta Bilota 20). Flanbesa hapaxa ilunsko da; beharbada flambàr «homme fringant, qui fait " de l'épate "» (Palay, s.v.) formari lot daiteke. Diablesa flanbesa bokatibozko sintagman atzemateak zentzuaren ideia bat iradoki lezake. 
gramatikala barneratzen baitu. Urgellek fenomeno hori tratatzen du, Añibarroren santa forma markatuaren erabilpena iruzkindurik ${ }^{10}$.

Kategoria gramatikalak denaz bezainbatean, printzipioz bizidunen izenek hartzen ahal dute $-s a$ atzizkia. Testuetan, alta, arau horren kontradibiderik ageri da (ostatü$s a$ 'emakume ostalari' $\leftarrow$ ostatï). Bestalde, erator ointzat hartzen diren hitzak jada euskararen barneko eratorriak direlarik, $-s a$ honako atzizkiei erantsirik ageri da: -AR (egoiliarsa, etxetiarsa), -ARI (arartekarisa, laborarisa, taharnarisa), -DUN (euskalduntsa), -GIN (emagintsa, okintsa), -KO (arartekosa), -TAR (larraintarsa, mauletarsa, xiberotarsa) eta -ZAIN (artzaintsa, eiherazaintsa).

\section{2. -sa-dun izenetarik eratorriak}

-sa-dun izenei bestelako atzizkirik eransteak bide bat eskaintzen du -sa atzizkia hizkuntzan noraino errotu den baloratzeko. Bestela errateko, genero bereizkuntza duten pareen gaineko eratorriak genero bereizkuntzaren estatusaren adierazgarritzat har litezke. Beraz, alhargüntsatu aditza ageri den hizkeretan alhargüntsa izenaren "osasuna» ona dela pentsa dezakegu: Monseigneur, alhargunxatu niçan guero nabi dit kitatu mundia (SteEli 1016); Hiriko emaztiac citiagu sarri alhargunxa eraciren! (SteEli 680). Mutatis mutandis, orobat gertatzen da beste aditz honekin: erregiñatü 'erregina bilakatu' $\leftarrow$ erregiña. OEHk Egiategiren adibide bat ematen du, eta honatx Eskiulan datatua den Sainte Elisabeth de Portugal trajerian kausitu dugun beste agerraldia: Eta balin eta ni ahal baniz erreguetcen, çoure baicic erreguignatcera ihouren eztit phenxatcen (SteEli 1453) $)^{11}$. Gogora bedi -al-o oposizioaren araberako pare lexikoetatik ere aditzik eratorri dela $(\mathbb{S} 3.1)$.

Orobat gertatzen da saintü/sainta paretik eratorriak diren saintütarzüna vs. saintatarzüna izenetan: Saintatarçuna bera çuçun horren bihotcian (SteEli 1325), baina saintutarçuna (SteEli 198, 826 \& 1021); guztiek Elisabeth erreginari erreferentzia eginik, ulertu behar da saintutarçun forma ez-markatua dela. Laburki, genero bereizkuntzaren ondoriozko hitz baten gaineko eratorriak ez dira anitz. Halere, azaleratu direnak genero markatua duten izen multzo murritz baten sendotasunaz mintzo dira.

10 «Geroko Geroren barruan Esku Liburuaren artean antzemandako aldaketa horren tankerako bilakaera bat dago: santa gero eta gutxiago, gero eta esapide jakinetan baino ez erabiltzeko joera handiagoa somatzen da. Izan ere, lehen buruetan hainbat dira femenino markadun izenondoa eraman dezaketen hitzak: Escritura Santa (0-37), christiñau-legue santa catoliquea (0-98/99), bere ama santearen negarrac (3-122), misericordia santearen señale andi bat (9-187/188), Elessa Santatic (11-29), Elessa Ama Santa (11-159), Susana andra santeac (11-238/239). Azken buruetan, aldiz, esan daiteke elessa (ama)-k bakarrik atxiki duela: Elessa Ama Santaren (38-55), Elessa Ama Santeac (42-56), Elessa santeac (46-47), Escritura santea (47-4), Elessa santan (47-151), Elessa Ama Santeac (47-159), Elessa santeac (47-184), Elessa Ama Santeac (47-186), Elessa Ama Santeac (50-52). Pare bat hitzek erakutsiko digute bilakaera nolakoa izan den. Argiena lege da, une batetik aurrera beti santua baita [...]. Atzera-aurrera dabil, ordea, hasiera-hasieratik escritura-rekin» (Urgell, 2001, XCI-XCII. orr.).

11 Perpausaren interpretazioa: 'zure beste inoren [TOGEN] ez dut erreginatzea [= erregina ezartzea] pentsatzen'. 


\subsection{Semantikaz bi hitz}

Printzipioz, -sa morfemak 'X femenino' erran-nahia konferitzen die bere eratorriei. Ikusi denez $(\mathbb{S} 5)$, -sa dutenak forma femenino markatuak dira, gehienetan -sa gabeak (ez-markatuak) maskulino zein femeninoa adierazteko erabili izan baitira. Balio nagusi horretaz gainera, -sa-dun batzuek bestelako kutsurik hartu dute. Bada, kapitainsa ez da 'emakume kapitain', baizik eta 'kapitainaren esposa', eta orobat erran daiteke harginesa edo zapataginesa hitzez. Hona hemen 1780an zer den sakristainsa bat: Badate orano sacristainsa bat, linge sacristaignac remetituco deronaz soeing ukheiteco (Mercy 36).

Familia izenekin -sa atzizkiaren erabilera hautazkoa bide da Zuberoan: «Xilo, M. Chilo; Xilosa, la femme de Chilo. Mais on dit mieux Xiloren emaztia, la femme de Chilo» (Larrasquet, 1939, s.v. -sa). Larrasqueten hitzetarik konprenitzen da -sa atzizkiak konnotazio negatibo bat adieraz dezakeela. Ekar dezagun horren adigarri bat: XX. mende hastapeneko Frantzian Caillaux izeneko ministro baten esposak kazetari bat hil zuen. Honatx gertakizuna, Hiriart-Urrutyk aipatua (Eskualduna, 1914-03-20): «Ministrosa, Caillausa delako Madama moda berrikoak hor hil duen gizona kazetari bat zen, Figaro deithu paristar kazeta handiaren egile buruzagia, Calmette izena zuena ${ }^{12}$ ».

\section{7. -SA ATZIZKIAREN HALA-MODUZKO ESTATUSAZ}

Eusko Jaurlaritzaren Emakunde institutuak euskararen «erabilera ez-sexista» deitu dutenaren gida plazaratu du; hor -sa atzizkiaren «arazo» bikoitza berriz ere gelditzen da agerian: "Atzizkia daramaten hitz batzuk, bestalde, berriak dira edo maileguak. [...] Baliteke hedatze hori politikoki zuzena izateko joerarekin lotuta egotea eta gaztelanian eta frantsesean emakumeak izendatzeko aldarrikapenekin zerikusirik izatea, baina bide hori ez doa euskararen izaerarekin bat eta hizkuntzak ez du estrategia hori behar» (Barquín, 2008, 28. orr.). Analisi horrek -sa atzizkiaren erabileraren hedakuntzaren arrisku potentzial bat seinalatzen du: «atzizkia erabiltzeak ondorio bat dauka: -sa atzizkirik gabeko izena maskulino bihurtzen du» Barquín, 2008, 28. orr. Juanena ere genero gramatikalaren ondorioez mintzo da:

Hizkuntz sexismoaz ihardun dutenek genero gramatikalaren arriskua azpimarratu dute batipat: horrelako hitzak erabiliz gero, eta diskriminazioa saihestu nahi baldin bada, biak errepikatzea eskatzen da: aktore-aktoresak, alkate-alkatesak, eta abar. Gauza da euskarak ez duela berez horrelako bereizketarik eskatzen, zenbait kasu konkretutan ezik. Eta larriago dena, kasu konkretu horietan, erdararen eraginez orain ere, galtzen hasi da euskal hiztunak errekonozitu ohi duen pare kidetasuna: seme-alabak, osaba-izebak eta antzeko hitz elkartuak elkartasuna hasi dira galtzen. (Juanena, 1991, 98. orr.)

12 Balio konnotatu hori yiddishak errusiera mailegatutako -ixe atzizkian ere deskribatu da: léjbixe 'lehoisa' edo Léjbixe 'Leyben emaztea' izan daiteke; cfr. 5. oharra. 
Araugintzari dagokionez, euskarak garatu duen genero bereizkuntzaren gaineko jarrera ofiziala ondoko pasartean esplizitatua da:

Euskarak ez du jenerorik bereizten gramatikan. Jenero gramatikala, inon bereiztekotan, aditzean bereziko da, hitanoan, hain zuzen: esan diat, baina esan dinat. Hortik aparte, euskaraz ez dago jenerorik. Beste hizkuntza batzutan morfologi bereizgarriak izaten dira jeneroa bereizteko. Euskaraz ez dago bereizketarik gizon eta emakumeren artean, lexikotik kanpo. Bereizketa hori lexiko mailan soil soilik gertatzen da: gizon eta emakume bi izen desberdin dira eta bakoitzak esanahi desberdina du: batak arra den izaki bat aipatzen du, besteak emea dena. Baina honek ez dakar morfologian inongo berezketarik. Eta zenbait euskaldunek bereizten dituzten alargun / alarguntsa, lehengusu / lehengusina eta antzekoak ere lexiko mailako berezkuntzak dira, gizon / emakume berezkuntzaren parekoak. Hitz hauek hiztegian markatuak etorri beharko dute, eta gramatikan ez dute inolako eraginik izango. Alde horretatik, zenbait hizkuntza mailatan egiten den bereizkuntza: tonto / tonta, katoliko / katolika eta abarrek, erdaratik hartuak direnez, ez dute lekurik eta ezin dute euskara batuaren gramatikaren bidea erakutsi, jakina baita erdaratikako adjetiboak euskaraz -o-z amaituta hartzen direla. (Euskaltzaindia, 1991, 36. orr.).

Azken hamarkadetako araugintzak eta hizkuntzaren «erabilera sexista» delakoaren gaineko kontzientzia berriak -menturaz elkarren lagun- ondorio praktikoak izan dituzte. Horrela, Egungo Euskararen Hiztegian LEHENDAKARISA xerkatuz gero honakoa ageriko da: "(Euskaltzaindiaren gomendioetan baztertzen dira -sa atzizkia duten formak) iz ipar emakumezko lehendakaria». Soilik jainkosa bezalako forma bakan batzuk salbuetsi dira -sa atzizkiaren gaitzeste orokorretik. Bistan da, Euskaltzaindiak egin du gaitzespena; beraz, Hiztegi Batuak halako aholkuak ematen ditu, adibidez ALARGUNTSA sarreran: «h[obe] alargun».

Ber maneran, eta anekdota gisara, euskaraz lan egiteko softwareari begira diezaiokegu. Microsoften euskara zuzentzailea baliatzean -2016an bederen-, OEHko 84 formetarik 17 baizik ez ziren onartuak: abadesa, alarguntsa, artxidukesa, artzaintsa, atezaintsa, baronesa, bizkondesa, dizipulusa, dukesa, errientsa, jainkosa, kantiniersa, kondesa, lehoisa, markesa, ostalertsa \& printzesa. Batetik, iduri du tradizio sendoko hitz batzuk errespetatu dituztela (alarguntsa, artzaintsa, jainkosa). Horren parean, nola esplika dizipulusa onartzea eta ez profetesa? Zergatik lehoisa bai, baina ez tigresa? Bestalde, ez dute -ari edo - gin atzizkien bidez eratorrien gaineko -sa-dun formarik onartu; bai, ordea, -er morfema duten ogibide izen batzuekin (kantiniersa, ostalertsa baina ez bulanjersa).

\section{8. -SA MORFEMA, ORAINO EMANKOR}

Deus baino lehen, egungo ekialdeko euskararen gaineko ikerketa soziolinguistikoren mentsean, preseski adierazi nahi dugu atal honetako datuen balioa subjektiboa dela. Zilegi bekigu, halere, han-hemen atzeman ditugun -sa atzizkiaren erabilpenaren adigarri batzuk ekartzea, ekialdeko egungo hiztunek -bereziki zuberotarrek- morfema 
horrekiko duten jokabidearen erakusgarri direlakoan. Iduriz, denak ez dira kontent -sa morfemaren emankortasun berri horrekin; zubereraren autoritate kalitatean JeanLouis Davanten hitzak dakartzagu:

Jokolarisa: hara egün hauetan ikasi düdan hitz berria. Eüskal media batetik zen, emazteen arteko errügbi partida baten (komentario) iruzkinean. Beraz txorien gripa bezain laster hedatüko zaigü, kantarisa eta lehendakarisa egin zaizgün bezala. Dendarisa ere entzün üken düt zonbait aldiz, dendaria beti anderea delarik alta, jostüna denean. Norat ari gira hola? Noizko arren emaztesa, anderesa, eta zeren ez amasa?

Emakunde deitzen den erakunte feministak hortara deitürik, Eüskaltzainak -sa atzizki horren hedatzea baztertzen dü üsatü hitzetarik harat. Sexista da, diskriminazalea, bereizlea. Eüskaraz ez da maskülino (ar) eta feminino (eme) generorik, salbüespen horik ekialdeko eüskalkietan dütügü haboroenik, hots behenafarreraz eta zübereraz, dela herritargoan (eüskaldüntsa, xiberotarsa), dela ofizio elibaten izenetan [...].

Erran delako -sa atzizki hori üsatüz kanpo erabilten dügülarik eüskaldün zaharrek, ez da konplimentüz. Hala nola Bordabeherako etxekandereaz erraiten delarik bordabeherasa, ez da haren goratzeko, aitzitik emazte arrunta dela erraiteko da, agian züzen kontre. Bena mintzajeaz ari niz heben, eta ez beste zerbaitez, bereziki ez andere baten balizko mail eskasaz. Haatik iparralde hontan, nor behatzen da orano Euskaltzaindiaren aholküer eta ni bezalako zaharroten erraner? ${ }^{13}$ (Davant, 2006).

Usadio horren adigarri batzuk aipatuko ditugu. Horrela, Zuberoako AEK-k antolatu ikastaldiari buruzko inpresioak kontatzean, gipuzkoar batek irakasleak bere burua aurkezten dueneko mementoa dakar: «Nor hiz hi? Eta nor bestea? Ni Odette Mohorade irakaslesa nük eta hau Jean Claude Sehebiague, eta horko hori Jüje Etxebarne» (Aurkenerena, 2003, 23. orr.). Halaber, Herria aldizkarian ez da batere arraro -sa formarik aurkitzea; hona 1990eko hamarkadako lau etsenplu:

- Joan ditela, haize hegoa lagun, gure pilotarisak. Gora atxik dezatela gure omena eta oroz gainetik izan ditela, gal edo irabaz, plaza-andere. («Emazteak Munduko Xapelgoan», Herria, 1990/10/25)

- Hogeita-hamar bat aizalek irauntsi die lehiaketa hortan, bi epaile aitzinean, Ernest Alkat bertsulari famatüa eta Itxaro Borda eleberri izkiribazalea eta olerkarisa, biak Basa Nabarrakoak. («Xiberoko Botzaren besta», Herria, 1993/5-13)

- Buberreki beste langile bat bada, idazkarisa (sekretarisa) bat, ekoizpeneko azken lanak egiten dütüanak ere. («Made in Euskal Herria marka duen ekoizteak», Herria, 1995-6-1)

13 2011. urtean Davant Ahotsak proiektuan elkarrizketatu dute, «-sa atzizki femeninoari buruz» izenburua duen bideoan ikusgai delarik (http://www.ahotsak.eus/urrustoi-larrabile/pasarteak/ula-002-015/). Atzizkiaren erabileraren inguruan Iparraldean dagoen «anarkiaz» mintzo da. Ondoko aipamenak, Jean Pujo ikastetxearen webgunetik hartuak, Davanten ideia ilustra lezakete: «Argitalpen zuzendaria: Nadine Ambielle anderea, ikastetxeko zuzendarisa» («Legezko abisuak», <http://college-pujo.11vm-serv.net/articles. php?lng=eus\&pg=15>, eta «Ikastetxeko kirol elkartearen zuzendarisa M. Monga anderea da, eta kiroleko erakasle den Aurelie Boudes jaunak du animatzen» («Ikastetxeko bizitza. Kirol Elkartea», <http://college-pujo.11vm-serv.net/articles.php?lng=eus\&pg=29>) [azken kontsulta: 2016-05-02]. 
- Eskandala sortu da lehen ministroaren erantzun bati esker, bortizki mintzatu delarik Boutin andere diputatuaren kontra (ez dut idazten diputatusa). Andere diputatua hurtu da nigarrez eta gero xutitu eta joan da lehen ministroaren gana, bainan uxerra hor ziren bidearen hesteko. («Telebixta leihotik», Herria, 1998-12-10)

Zuberoako egungo literaturan ere usu ageri dira -sa atzizkidunak. Itxaro Bordaren eleberriek guk egin ez dugun azterketa merezi lukete; bestenaz, eta etsenplu batentzat, hona Bedaxagarren Alienor pastoraleko pasarte bat: Beti herritik jin dira zaldünak eta zaldüntsak! 'chevaliers et amazones' (80) \& Zaldüntsa arrahent honek ederrik ditu biloak! 'cavalière' (194). Junes Casenave-Harigilek maiz erabili zituen -sa-dun formak; lan batekoak baizik ez aipatzeko, bihoaz honako hauek, haren latin-euskara hiztegitik hartuak -parentesi artean latinezko sarrerak-: agintarisa (IMPERATRIX), alarguntsa (ORBUS), antzezlarisa (MIMULA), arartekarisa (ORATRIX), aztisa (DIVINA), beoziarsa (AONIS), doridarsa (DORIENSES), ehiztarisa (JACULATRIX), grekosa (DORIENSES), greziarsa (ACHAIS), gudarisa (BELLATRIX), kantarisa (CANTATRIX), korteliarsa txistulariak (AMBUBAIAE), kretarrarsa (CRESSA).

Kostaldetik hurbilago ere, eta guztiz gure denboran, ageri da -sa-dunik: «Lau jokolari eta jokolarisa bat aldizka gizon edo emazte diren pertsonaia batzuentzat. Irrealitaterat jauste bat hasten dugu serioski» (Les Translatines antzerki jaialdiaren egitaraua, Baiona, 2009). Ber hitza Hendaian ere: «Jokolarisa, margolari eta musikari baten inguruan, publikoa testu bidaia baten bizitzera gomitatua izanen da, hiri erdietatik urrun» (Mai du Théâtre - Antzerkiaren Maiatza jaialdiaren egitaraua. Hendaia, 2015).

\section{ONDORIOAK}

Zuberoako euskara historikoaren corpusak (XVI.-XIX. mendeak) -sa atzizki eratorleaz gauzatzen den genero bereizkuntza testuetan ohikoa dela erakusten du, morfema hori azken mendeetan emankor izan baita. Testuetan -sa atzizkiaren aro oparoena XVIII. mendea bide da. Orotariko Euskal Hiztegiari erkaturik, ageri da -sa-dun forma gehienak ekialdeko euskalkietakoak direla; halaber, gure corpusak OEHk jaso ez duen beste zenbait forma lekukotzen du.

-sa morfemarekin eratorpenezko generoaz aritu bagara, mendebaldeko mintzoetan erroak eman dituen -o/- $a$ bukaeren araberako genero bereizkuntzak urrats bat gehiago inplikatzen du, hots, inflexio morfemen mailegatzea, soilik hizkuntzen arteko ukipen egoera bereziki azkarretan gerta daitekeena. Horregatik inflexio morfemak mailegagarritasun eskalen goienean kokatzen ohi dira; horri lotuz, munduan gutxi dira genero gramatikala maileguen ondorioz garatu duten hizkuntzak.

Azken finean, mendebaldeko euskararen -o/-a morfemak bezala, -essa atzizki erromantzea euskaran sartu eta errotu izatea ukipen egoera luze eta azkarraren ondorio naturala da: Erdi Arotik euskaldunak morfema zenbaitez baliatu dira izen batzuen generoaren markatzeko. Aldiz, hiztunentzat natural izan denak azken hamarkadetan bi joerarekin talka egiten du: batetik garbizaletasuna -morfema horiek mailegatuak dira, 
eta gainera hizkuntzari arrotz zitzaion ezaugarri gramatikal bat sarrarazten dute-, eta bestetik feminismoa -generoaren markatzea euskararen «erabilera sexista» litzateke-. Halere, iduri du egungo zuberotarrek hitz berriak eratortzen jarraitzen dutela -sa morfemaren medioz, beharbada beren hizkuntza nortasunari lotua sentitzen baitute.

\section{ERREFERENTZIAK}

Aurkenerena, J. (2003). Iparraldeko kronikak. Bilbo: Mensajero.

Azkue, R. M. (1905). Diccionario vasco-español-francés. Bilbo.

Azkue, R. M. (1923). Morfología vasca. Bilbo: Editorial Vasca.

Barquín, A. (2008). Euskararen erabilera ez sexista. Vitoria-Gasteiz: Emakunde.

Bueno, A. (2011). Nominalizazio atzizki deitutakoen azterketa historikoa eta morfologikoa. In J. A. Lakarra, J. Gorrochategui \& B. Urgell (arg.), Koldo Mitxelena Katedraren II. Biltzarra (Gasteiz, 2007ko urriaren 8tik 11ra) (191200. orr.). Bilbo: UPV/EHU.

Casenave-Harigile, J. (2002). Latina-Euskara Hiztegia. Bilbao: Euskaltzaindia. Hemendik hartua: http://www.euskaltzaindia.eus/dok/iker_jagon_tegiak/77389.pdf

Comrie, B. (2008). Inflectional morphology and language contact, with special reference to mixed languages. In P. Siemund \& N. Kintana (arg.), Language Contact and Contact Languages (15-32. orr.). Amsterdam \& Philadelphia: John Benjamins.

Coyos, J.-B. (2008). Zubereraren eta biarneraren arteko harremanez: lexiko mailegatua eta ahoskatzea - Lehen balantzea. In. A. Sagarna, J. Lakarra \& P. Salaberri (arg.), Pirinioetako hizkuntzak: oraina eta lehena (919-949. orr.). Bilbo: Euskaltzaindia.

Davant, J.-L. (2006-3-7). Emaztesa. Le Journal du Pays Basque. Hemendik hartua: http://www.lejpb.com/idatzia/20060307/art154617.php

De Rijk, R. P. G. (1991). Deux suffixes capricieux : -pen et -men. In J. A. Lakarra \& I. Ruiz Arzalluz (arg.), Memoriae L. Mitxelena Magistri Sacrum (709-752. orr.). Donostia: Gipuzkoako Foru Aldundia.

Eliasson, S. (2012). On the degree of copiability of derivational and inflectional morphology: Evidence from Basque. In J. Lars \& M. Robbeets (arg.), Copies versus Cognates in Bound Morphology (Language and Linguistics EBooks Online - Brill's Studies in Language, Cognition and Culture, vol. 2, 257-296. orr.). Leiden: Brill.

Euskaltzaindia. (1991). Euskal Gramatika. Lehen Urratsak - I. Bilbo: Euskaltzaindia.

Field, F. W. (2002). Linguistic borrowing in bilingual contexts. Amsterdam/Philadelphia: John Benjamins.

Gardani, F. (2008). Borrowing of Inflectional Morphemes in Language Contact. Frankfurt: Peter Lang.

Gardani, F., Arkadiev, P. \& Amiridze, N. (2014). Borrowed Morphology. Berlin: De Gruyter Mouton.

Haase, M. (1992). Sprachkontakt und Sprachwandel im Baskenland: die Einflüsse des Gaskognischen und Französischen auf das Baskische. Hanburgo: Helmut Buske. 
Hualde, J. I., Elordieta, G. \& Elordieta, A. (1994). The Basque dialect of Lekeitio. Donostia: UPV/EHU \& Gipuzkoako Foru Aldundia.

Juanena, A. (1991). Hizkuntz sexismoa eta euskara. Jakin, 65, 97-110.

Lafon, R. (1947). Remarques sur la catégorie de genre grammatical en basque. Bulletin Hispanique, 49(4), 373-394.

Larrasquet, J. (1939). Le basque de la Basse Soule Orientale. Paris: Klincksieck.

Lindsay, M. \& Aronoff, M. (2013). Natural selection in self-organizing morphological systems. In F. Montermini, G. Boyé \& J. Tseng (arg.), Morphology in Toulouse: Selected Proceedings of Décembrettes 7 (133-153. orr.). München: Lincom Europa.

Manterola, J. (2015). Euskararen morfologia historikorako: artikuluak eta erakusleak - Towards a history of Basque morphology: articles and demonstratives. UPV/EHUko doktorego tesia.

Matras, Y. (2007). The borrowability of structural categories. In Y. Matras \& J. Sakel (arg.), Grammatical borrowing in cross-linguistic perspective (31-73. orr.). Berlin/New York: Mouton de Gruyter.

Matras, Y. (2009). Language contact. Cambridge: Cambridge University Press.

Mitxelena, K. (1954). De onomástica aquitana [berrarg. in OOCC V, 197-243. orr.].

Mitxelena, K. (1957). El genitivo en la onomástica medieval. Emerita, 25, 134-148 [berrarg. in OOCC IX, 429-441. orr.].

Mitxelena, K. (1974). El elemento latino-románico en la lengua vasca. FLV, 6, 183-209.

Mozos, I. (1986). Ihauteria euskal literaturan. Donostia: Eusko Ikaskuntza.

Palay, S. (1998). Dictionnaire du béarnais et du gascon modernes (bassin aquitain), embrassant les dialectes du Béarn, de la Bigorre, du Gers, des Landes et de la Gascogne maritime et garonnaise. Paris: CNRS.

Reguero, U. (2012). Erdi Aroko euskararen historia kanpotik eta barnetik. ASJU, 46(2), 63-160.

Sakel, J. (2007). Types of loan: matter and pattern. In Y. Matras \& J. Sakel (arg.), Grammatical borrowing in cross-linguistic perspective (15-29. orr.). Berlin/New York: Mouton de Gruyter.

Seifart, F. (2013). AfBo: A world-wide survey of affix borrowing. Leipzig: Max Plank Institute for Evolutionary Anthropology. Hemendik hartua: http://afbo. info

Thomason, S. G. \& Kaufman, T. (1988). Language Contact, Creolization, and Genetic Linguistics. Berkeley: University of California Press.

Trask, R. L. (2003). The Noun Phrase: nouns, determiners and modifiers; pronouns and names. In J. I. Hualde \& J. Ortiz de Urbina (arg.), A Grammar of Basque (113-170. orr.). Berlin \& New York: Mouton de Gruyter.

Urgell, B. (2001). Fr. Pedro Antonio Añibarro. Gueroco Guero. Edizio kritikoa. Bilbo: Euskaltzaindia.

Urgell, B. (2004). Etimologia eta neologia Larramendiren Hiztegi Hirukoitz-ean (1745). Lapurdum, 9, 299-310.

Urkizu, P. (1998). Zuberoako irri teatroa. Baigorri: Izpegi. 